\title{
EDITORIAL
}

\section{Possibility of transmission through dogs being a contributing factor to the extreme Covid-19 outbreak in North Italy}

\author{
MARINA GOUMENOU ${ }^{1}$, DEMETRIOS A. SPANDIDOS ${ }^{2}$ and ARISTIDIS TSATSAKIS ${ }^{1}$ \\ ${ }^{1}$ Center of Toxicology Science and Research, Medical School, University of Crete, 71003 Heraklion; \\ ${ }^{2}$ Laboratory of Clinical Virology, Medical School, University of Crete, 71409 Heraklion, Greece
}

Received March 20, 2020; Accepted March 23, 2020

DOI: $10.3892 / \mathrm{mmr} .2020 .11037$

\section{Covid-19 origin and transmission to humans}

Covid-19 infection began in Wuhan (Hubei, China) in December, 2019. Although to date it is considered that Covid-19 originates from bats $(96.2 \%$ overall genome sequence identity) (1), the type of intermediate animals that caused the transmission to humans remains unknown (2-4). Zhou et al (1) mentioned that 'Direct contact with intermediate host animals or consumption of wild animals was suspected to be the main route of SARS-CoV-2 transmission. However, the source(s) and transmission routine(s) of SARS-CoV-2 remain elusive' (1).

\section{Covid-19 in Italy}

In Italy, the first two cases were entered on January, 23 and were identified in January 29, 2020. Until February 24 the positive cases identified were 221 . Despite the fact that a number of restrictive measures have been taken for preventing the gathering of individuals, or even preventing their circulation out of the house, at almost 1 month from that time (March 20, 2020), the number of positive cases increased to 37,860 (with 4,035 deaths, more than those occurring in China) and a plateau in the respective curve has not yet been reached (5) (Fig. 1).

\section{9-nCoV and the ACE2 receptor}

SARS-CoV-2 is a $\beta$-coronavirus similar to SARS-CoV $(79.5 \%$ shared identity) (4). Viral infection begins with an initial attachment step, namely the binding of the virus to the respective host cell receptor. SARS-CoV has been studied since

Correspondence to: Dr Marina Goumenou, Center of Toxicology Science and Research, Medical School, University of Crete, 71003 Heraklion, Greece

E-mail: marina.goumenou@gmail.com

Key words: Covid-19, dogs, transmission, ACE2, Italy, cross-species transmission the outbreak in 2002. It is well known that the virus enters cells through the binding of its spike protein receptor-binding domain (RBD) to the angiotensin-converting enzyme 2 receptor (ACE2). Although the 2019-nCoV RBD has not yet been fully investigated, it shares same common characteristics with SARS-CoV and it has the ability to bind to human ACE2 (6). ACE2 receptors exist in a number of animals and this is the reason why inter-species contamination is possible. The efficiency of this binding depends on the affinity between the RBD of the virus and the species-specific ACE2. Although it is already known that rats and mice are not susceptible, the issue of Covid-19 RBD recognition of ACE2 of dogs remains unresolved.

Covid-19 human-to-animal and animal-to human transmission

To our knowledge, the only available information for Covid-19 in dogs is derived from Hong Kong. On February 27, a Pomeranian was tested as weak positive for Covid-19 from the Agriculture, Fisheries and Conservation Department of Hong Kong (7). It is believed that dog's infection was possibly due to transmission from his infected owner (a human-to-animal transmission). The dog remained under quarantine and samples taken on February 28 and on March 2, were again weak positive, confirming the case of infection (instead of just mouth and nose contamination from the household). The dog was asymptomatic during the whole period of infection. The AFCD of Hong Kong stated: 'Although there is no evidence yet that pets can transmit the virus to other pets or back to humans, we strongly advise that mammalian pets including dogs and cats from households with persons confirmed as infected with COVID-19 or as close contacts of COVID-19 infected persons should be put under quarantine in AFCD facilities to safeguard public and animal health. We will review this arrangement from time to time taking into account new information that becomes available' (7).

The American Veterinary Medical Association mentions: 'This pet dog was one of two pet dogs under quarantine. The second pet dog had negative results of tests for the virus. Neither dog showed any signs of being ill with COVID-19. 


\section{Aipartimento della Protezione Civile}

COVID-19 Italia - Monitoraggio della situazione

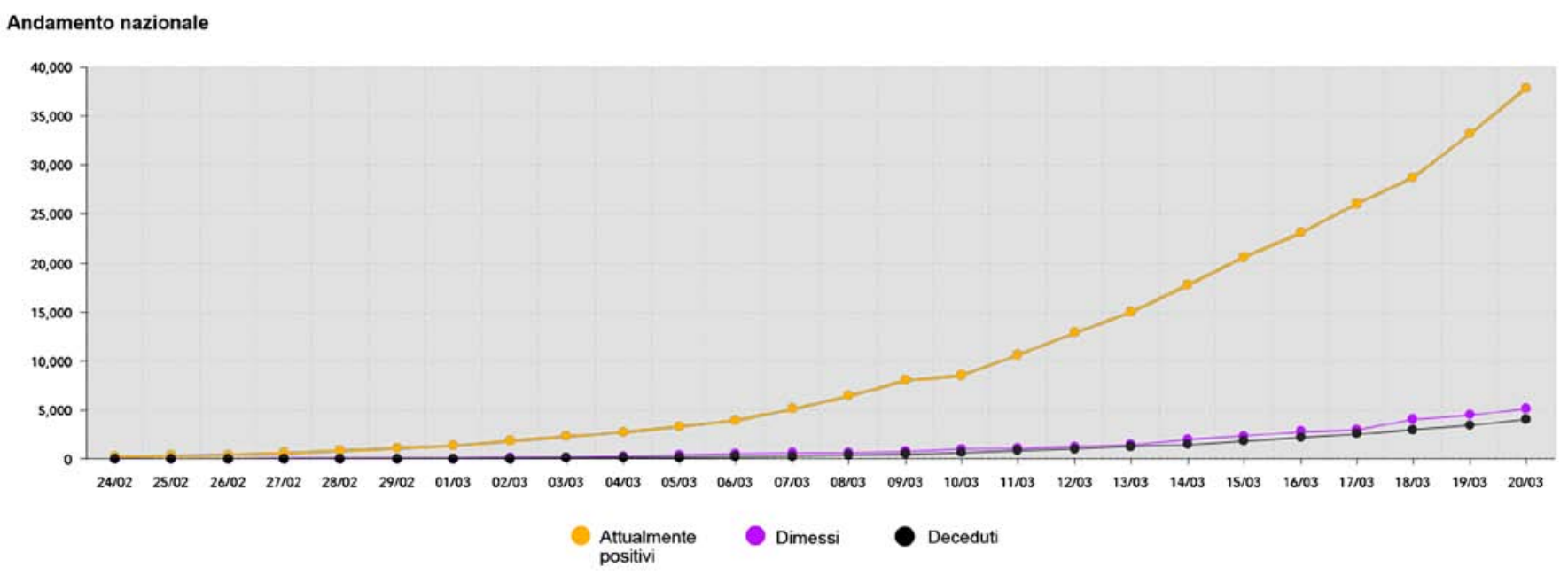

Figure 1. Covid-19 cases monitoring from February 24, 2020 to March 3, 2020

Unfortunately, the dog that tested positive passed away on March 16. The dog was 17 years old and had ongoing health issues that were likely responsible for the death of this dog, rather than COVID-19. We are told the second pet dog has been released from quarantine. On March 19, the AFCD reported that a third dog, a German Shepherd Dog living with an owner testing positive for COVID-19, had also tested positive. Another mixed-breed dog from the same residence tested negative. Neither dog has shown signs of disease. Both dogs are in quarantine and are continuing to be monitored and tested', 'To date, there have not been any reports of pets or other animals becoming ill, and there is no evidence that domestic animals, including pets, can spread SARS-CoV-2. Because the situation is ever-evolving, public and animal health officials may decide to test certain animals out of an abundance of caution. The decision to test will be made collaboratively between local, state, and federal animal and public health officials', 'After the decision is made to test, state animal health officials will designate a state-appointed veterinarian, USDA-accredited veterinarian, or foreign animal disease diagnostician to collect the sample using appropriate personal protective equipment (PPE) and sample collection methods', 'While we are recommending these as good practices, it is important to remember that, to date, there have not been any reports of pets or other animals becoming ill with SARS-CoV-2, and there is currently no evidence that pets can spread COVID-19 to other animals, including people' (8).

The World Organisation for Animal Health (WOAH) claimed: 'To date, there is no evidence that companion animals can spread the disease. Therefore, there is no justification in taking measures against companion animals which may compromise their welfare. There is no evidence that dogs play a role in the spread of this human disease or that they become sick. Further studies are needed to understand if and how different animals could be affected by COVID-19 virus. The OIE will continue to provide updates as new information becomes available. However, because animals and people can sometimes share diseases (known as zoonotic diseases), it is still recommended that people who are sick with COVID-19 limit contact with companion and other animals until more information is known about the virus' (9). WHO stated there is no evidence to indicate that animals such as dogs or cats can be infected with the coronavirus.

The Italian Health Ministry (IHM) announced that: 'To date, there are neither evidences that animals, like dogs and cats, can be infected by SARS-CoV-2, nor that they can be a source of human infection', 'It cannot be excluded the dog was infected by its owner'. Indeed, for reasons of precaution (10). CDC advise 'You should restrict contact with pets and other animals while you are sick with COVID-19, just like you would around other people. Although there have not been reports of pets or other animals becoming sick with COVID-19, it is still recommended that people sick with COVID-19 limit contact with animals until more information is known about the virus. When possible, have another member of your household care for your animals while you are sick. If you are sick with COVID-19, avoid contact with your pet, including petting, snuggling, being kissed or licked, and sharing food. If you must care for your pet or be around animals while you are sick, wash your hands before and after you interact with pets and wear a facemask'.

David Grimm, the Online News Editor of Science, interviewed Shelley Rankin, a microbiologist at the University of Pennsylvania School of Veterinary Medicine (11). Dr Rankin mentioned: 'It was a single case, and we learned that we need to do a lot more research into the potential of the human SARS-CoV-19 virus to infect animals. That said, cats and dogs are mammals too. They have many of the same types of receptors on their cells that we do. So the virus could theoretically attach to these receptors. But will it enter their cells and replicate? Probably not. Still, people infected with SARS-CoV-19 should limit contact with their pets. Wash your hands, and don't let them lick you on the face. If the virus is in your secretions, and there's any potential of transmission, these are ways it could be transmitted'. Speaking for the need of testing pets she said: 'That's [not] everybody's top priority 
right now. It should be discussed, however, if we start seeing more cases like the Hong Kong Pomeranian'. Responding in the question if pets can serve as a reservoir of the virus and pass it back to us she responded that 'If pets can become infected - and we don't know if they can - then yes, they could serve as a reservoir. And in that case, we'd need to deal with them the same way we're dealing with human cases. We'd need to figure how to treat them. Like human hospitals, vet hospitals would have to be prepared for a surge in the number of cases' (11).

It is known that SARS-CoV can infect domestic cats and lead to transmission between them, although without manifestation of symptoms (12). Although data for SARS infection to dogs could not be found, there are data available to support that dog ACE2 has a $87 \%$ nucleotide identity and $81 \%$ amino acid identity with human ACE2, and also functions as a SARS-CoV receptor (13). In addition, it is generally known that various cell lines without ACE2 are still permissive for SARS-CoV, indicating the existence of more receptors. No data regarding this case in dogs are available.

\section{The question of whether dogs are possible intermediate hosts and whether this may related to the extremely high transmission in North Italy}

Italy is the second country in Europe (after Hungary) in which the possession of a pet is common, with $>50 \%$ of homes owning one (14). Owning a dog as a pet in Italy is extremely common. The available information refers to a total of c.a. 10.000.000 registered dogs (by tattoo or microchip), indicating c.a. 1 dog for every 6 individuals. As regards their distribution, 1.392.197 and 1.079.884, 1.172.344 of these cases are in Lombardia, Emilia Romagna and Veneto, respectively (15).

To summarise, it is known that: i) Globally, to date, only 4 dogs have been tested for Covid-19. These dogs had come into contact with infected individuals; ii) dogs have an ACE2 that functions as a SARS-CoV receptor; iii) dog ACE2 is similar to human ACE2; iv) the infection of animals from humans and vice versa is plausible; v) no data are available to confirm or exclude the possibility of such human-to-dog and dog-to-human infection; and vi) precautionary measures for such cases have been proposed from all authorities; however, it is highly questionable whether these are followed by dogs owners.

Although $>2$ weeks have already passed from the time when Italian authorities restricted citizen mobility, the exponential increase in the number of positive cases and deaths continues. To date, there is no satisfactory explanation for this phenomenon. Exception from the mobility restriction in all territories, is the mobility for taking out dogs. In a number of cases, this exception is over-used. Therefore, further than the every-day contact between dogs and Italian families, there is a constant more-than-one, every-day contact between animals and other owners.

All the above facts create the need to reconsider the possibility that dogs are intermediate hosts contributing to the extremely high Covid-19 transmission in North Italy. Possible actions to this direction could include the biased testing of dogs living in houses with positive cases opposed to home quarantine, and non-experimental studies for the investigation of such transmission, using appropriate methodologies such as in silico docking to evaluate the binding of Covid-19 with dogs ACE2 (16) and sequence-based computational estimations of hosts susceptibility (17).

\section{References}

1. Zhou P, Yang XL, Wang XG, et al: A pneumonia outbreak associated with a new coronavirus of probable bat origin. Nature 579: 270-273, 2020

2. Cyranoski D: Mystery deepens over animal source of coronavirus. Nature 579: 18-19, 2020.

3. Singhal T: A Review of Coronavirus Disease-2019 (COVID-19). Indian J Pediatr 87: 281-286, 2020.

4. Guo YR, Cao QD, Hong ZS, et al: The origin, transmission and clinical therapies on coronavirus disease 2019 (COVID-19) outbreak - an update on the status. Mil Med Res 7: 11, 2020.

5. Italian Civil Protection, 2020. http://opendatadpc.maps.arcgis. com/apps/opsdashboard/index.html\#/b0c68bce2cce478eaac82fe 38d4138b1.

6. Wan Y, Shang J, Graham R, Baric RS and Li F: Receptor Recognition by the Novel Coronavirus from Wuhan: An Analysis Based on Decade-Long Structural Studies of SARS Coronavirus. J Virol 94: e00127-20, 2020. https://doi.org/10.1128/JVI.00127-20 PMID:31996437.

7. Agriculture, Fisheries and Conservation Department (AFCD): New Updates on Low-level of Infection with COVID-19 in Pet Dog. https://www.pets.gov.hk/english/highlights/files/New_ Updates_on_Low-level_of_Infection_with_COVID-19_in_Pet_ Dog_0503__eng.pdf. Accessed March 5, 2020.

8. American Veterinary Medical Association (AVMA): SARS-CoV-2 and domestic animals, including pets. https://www. avma.org/resources-tools/animal-health-and-welfare/covid-19. Accessed March 21, 2020.

9. World Organisation for Animal Health (WOAH): Questions and Answers on the 2019 Coronavirus Disease (COVID-19). https://www. oie.int/en/scientific-expertise/specific-information-and-recommendations/questions-and-answers-on-2019novel-coronavirus/.Accessed March 9, 2020.

10. Italian Health Ministry (IHM): Covid-19: al momento non esistono prove che gli animali da compagnia diffondano il virus. http://www.salute.gov.it/portale/news/p3_2_1_1_1. jsp?lingua $=$ italiano $\&$ menu $=$ notizie $\& \mathrm{p}=$ dalministero $\& \overline{\mathrm{id}}=\overline{4} 1 \overline{3} 6$. Accessed March 2, 2020.

11. Science: Quarantine the cat? Disinfect the dog? The latest advice about the coronavirus and your pets. https://www.sciencemag. org/news/2020/03/quarantine-cat-disinfect-dog-latest-advice-ab out-coronavirus-and-your-pets. Accessed March 12, 2020.

12. Martina BE, Haagmans BL, Kuiken T, et al: Virology: SARS virus infection of cats and ferrets. Nature 425: 915, 2003.

13. Olivieri ER, Heller LK, Gillim-Ross L and Wentworth DE: Analysis of SARS-CoV receptor activity of ACE2 orthologs. Adv Exp Med Biol 581: 277-280, 2006.

14. La Stampa: Censis: nelle case degli italiani ci sono 32 milioni di animali domestici. https://www.lastampa. it/la-zampa/2019/04/03/news/censis-nelle-case-degli-italiani-ci -sono-32-milioni-di-animali-domestici-1.33692224?refresh_ce. Accessed April 3, 2019.

15. Habitante: Quanti cani ci sono in Italia? La lista di tutte le regioni (data for the Italian Health Ministry). https://www.habitante. it/habitante-consumatore/quanti-cani-ci-sono-in-italia-la-lista-di -tutte-le-regioni/. Accessed December 27, 2019.

16. Ralph R, Lew J, Zeng T,et al: 2019-nCoV (Wuhan virus), a novel Coronavirus: human-to-human transmission, travel-related cases, and vaccine readiness. J Infect Dev Ctries 14: 3-17, 2020.

17. Cho M and Son HS: Prediction of cross-species infection propensities of viruses with receptor similarity. Infect Genet Evol 73: 71-80, 2019.

This work is licensed under a Creative Commons Attribution-NonCommercial-NoDerivatives 4.0 International (CC BY-NC-ND 4.0) License. 